\title{
Adoption of Big data technology by water stakeholders in Morocco: An adaptation of the technology acceptance model.
}

\author{
Aniss MOUMEN ${ }^{1 *}$, Hajar SLIMANI ${ }^{2}$, Nezha MEJJAD ${ }^{3}$, Mohamed BEN-DAOUD ${ }^{4}$ \\ ${ }^{1}$ Laboratory of Engineering Sciences, ENSA Kenitra, Ibn Tofail University, Morocco \\ ${ }^{2}$ LEREMCE, ENCG Meknes, Moulay Ismail University, Morocco \\ ${ }^{3}$ Faculty of Sciences of Ben M'sik, Hassan II University, Casablanca, Morocco \\ ${ }^{4}$ Faculty of Sciences, Moulay Ismail University, Meknes, Morocco
}

\begin{abstract}
Nowadays, big data technologies are becoming increasingly important in the modernization of organizations' information systems. Indeed, water and climatology data producers and users deal daily with massive data processing. These actors need new technology to overcome the difficulties in data integration, processing and visualization. This paper presents an exploratory study about the intention to use big data technology by the water stakeholders in Morocco; we also present an exploratory review of technology acceptance model theory, a theoretical framework that explains the factors of adopting new technologies by users.
\end{abstract}

\section{Introduction}

The word "Big data" probably appeared from the 1990s [1], [2], used for the first time in 1989 by the American journalist and author of nonfiction books "Erik Larson", to describe the problem he was dealing with receiving massive emails. According to Doug Laney (2001) [3], Big data can be characterized by the following dimensions: Volume, Variety, Velocity, Veracity, Value and Variability. Other important characteristics of Big Data are: Exhaustive, Fine-grained and uniquely lexical, Relational, Extensional, Scalability.

Meteorology was the first scientific discipline to use and produce big data [4]. For example, The NASA Center for Climate Simulation (NCCS), Debuting in spring 2010, stores 32 petabytes of climate observations and simulations on the Discover supercomputing cluster.

In Morocco, the water sector is characterized by an important number of actors, which produce and use a huge dataset and a set of decision-support systems [5]. Also, the measurement of water resources and climatic parameters requires significant storage, processing and analysis resources [5]. Hence, using big data by these stakeholders will improve the performance and the quality of the service provided to the citizens [6].

This paper presents an exploratory study about the intention to use big data technology by the water stakeholders in Morocco; we also present a review of technology acceptance model theory, a theoretical framework that explains the factors of adopting new technologies by users.

\section{Acceptance Model Theory (AMT) for big data technology :}

AMT (Acceptance Model Theory) suggests that system or technology adoption can be explained by the user's motivations that are based on perceived system features and capabilities $[7,8]$. TAM has its origin in the theory of reasoned action [9] and the theory of planned behaviour [10]. The figure below summarizes the explained variables of acceptance of technology.

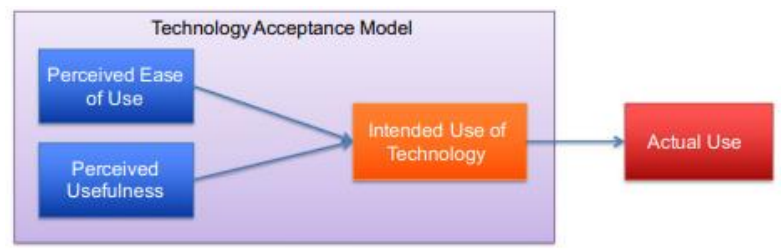

Fig. 1. Original technology acceptance model (Source: $[7,11]$ )

Many researchers are interested to study the acceptance of bigdata by organizations. Indeed, Kelly Wee Kheng Soon et al. [12], Vitor Brock and Habib Ullah Khan [13] propose a model derived from AMT to explain Big data adoption, which the components of organization learning capabilities influence the acceptance of bigdata technology (below the figure) : 


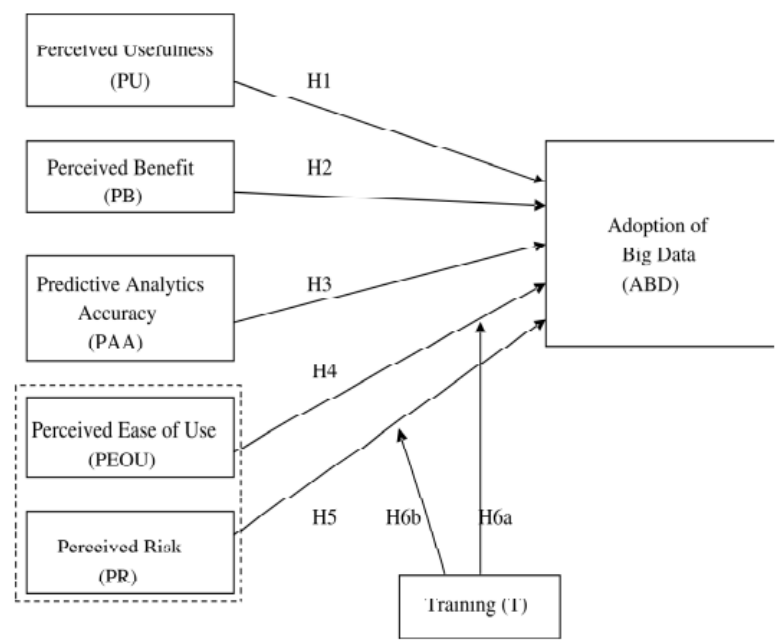

Fig. 2. The theoretical model was adopted by Kelly Wee Kheng Soon et al [12].

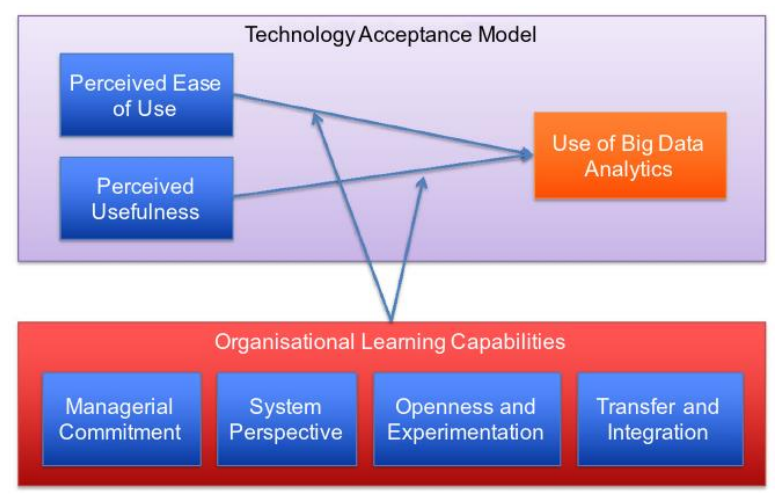

Fig. 3. The theoretical model adopted by Vitor Brock and Habib Ullah Khan [13].

Surabhi Verma et al. [14] suggest an extension version of AMT to explain the adoption of Big data analytics and confirm that characteristics of the big data analytics system have significant direct and indirect effects on belief in the benefits of big data analytics systems and perceived usefulness, attitude and adoption. Surabhi Verman et al. research model is presented below :

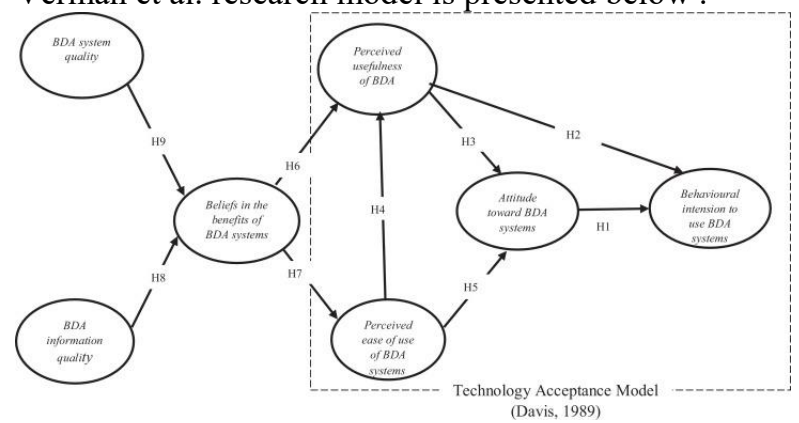

Fig. 4. The theoretical model adopted by Surabhi Verman et al. [14]

Serap Okcu et al. [15] conducted a study to identify the factors affecting the use of big data tools. According to this study, Perceived Usefulness and Perceived Ease of Use are explained by other factors like: Complexity, Anxiety, Compatibility, BDA Dimensions, Job Relevance and Self-efficacy. The figure below present the research model of Serap Okcu et al.

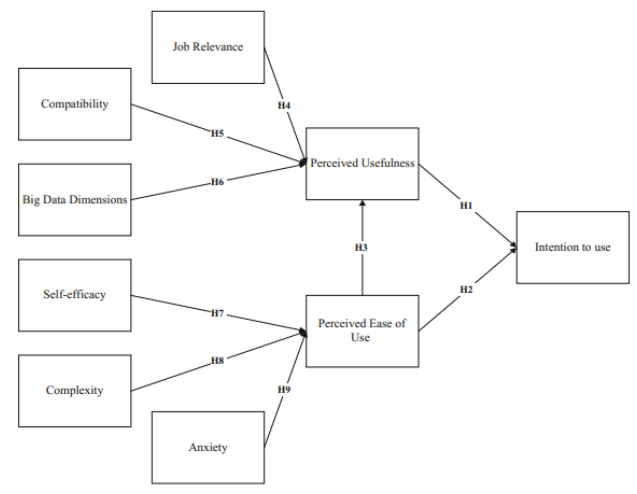

Fig. 5. The model adopted by Serap Okcu et al. [15]

\section{Water stakeholders in Morocco}

In Morocco, the National Water Strategy adopted in 2009 [16] defined the institutional framework for water stakeholders by attributing to the central administration (also called the water department) the mission of regulator. On the other hand, the water basin agencies created based on the 1995 water law [17] play a central role, at the regional level, in the integrated water resources management alongside the regional actors, such as ONEE, ORMVA, Water \& Forests Delegation, Meteorological Centers. In addition to these regional actors, there is also the "Wilaya" as representative of authority and responsible for coordinating the various external services [5], with the regional council and municipal councils representing the region's citizens. The figure below summaries all the water stakeholders in Morocco :

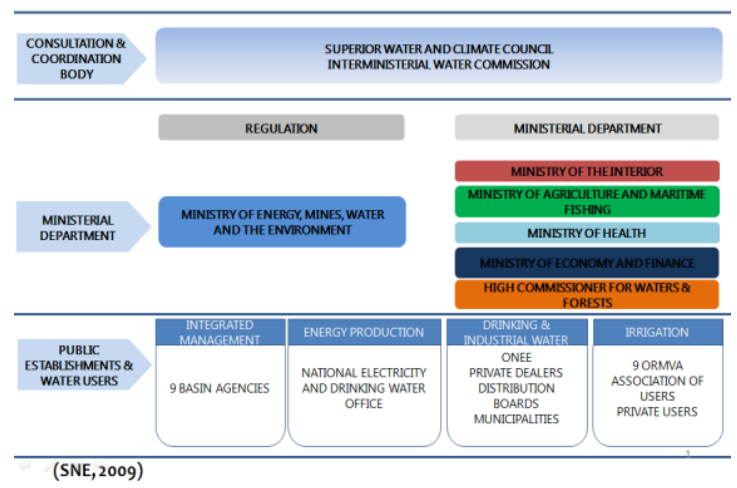

Fig. 6. Water stakeholders in Morocco [5].

According to this figure and the official documentations [18] we can conclude that the water sector includes a considerable number of actors, especially at the regional level :

Table 1. Estimations of the number of water stakeholders.

\begin{tabular}{|l|l|l|}
\hline & \multicolumn{2}{|l|}{ Number of actors } \\
\hline Central & \multicolumn{2}{|c|}{7} \\
\hline \multirow{4}{*}{ Regional } & ABH & 9 \\
\cline { 2 - 3 } & ORMVA & 9 \\
\cline { 2 - 3 } & ONEP & 10 \\
\cline { 2 - 3 } & Municipality & 266 \\
\cline { 2 - 3 } & Association of users & +1000 \\
\hline Total & \multicolumn{1}{|c|}{+1300 actors } \\
\hline
\end{tabular}




\section{Perception on Big data technology: Qualitative study}

\subsection{Interviewees :}

In July 2020 [19], we conducted in-depth interviews (The average duration was 20-30 $\mathrm{min}$ ) to collect (recorded by a digital voice recorder) the opinions on acceptance of big data technology of 5 collaborators from IT Services and Users from local authorities in charge of water resource management in South-Eastern Region of Morocco. The saturation was the criteria to define the size of our sample, and the list of topics that compose the interview is: "Usage", "Benefit" and "Constraint", related to "Big data". After transcription, we have constructed our text corpus and start the analysis by NVIVO.

\subsection{Perceptions on Big data :}

From these interviews [19], we can propose that the first motivation for adopting "Bigdata" by the public organizations is to improve citizens services, particularly responsiveness. At the same time, big data technologies may not be used soon, but relatively soon, according to our interviewees.

Also, we have pointed out that the notion of big data is quite clear for our interviewees, which explains that the motivation for use of Big data is to improve users' services. However, acceptance of big data will face many obstacles: legislative, organizational, technical and human. Also, data confidentiality and security are important requirements for using big data, according to our interviewees.

Finally, training should focus on: raising users awareness (decision-makers and employees) and technical training for data analysis, monitoring and maintenance of hardware and software platforms.

\section{Conclusion}

This paper presents the concept of big data and the importance for any organization dealing daily with huge data.

As a conclusion of this exploratory review and our qualitative study, we propose our model to explain how users can adopt big data in future cases.

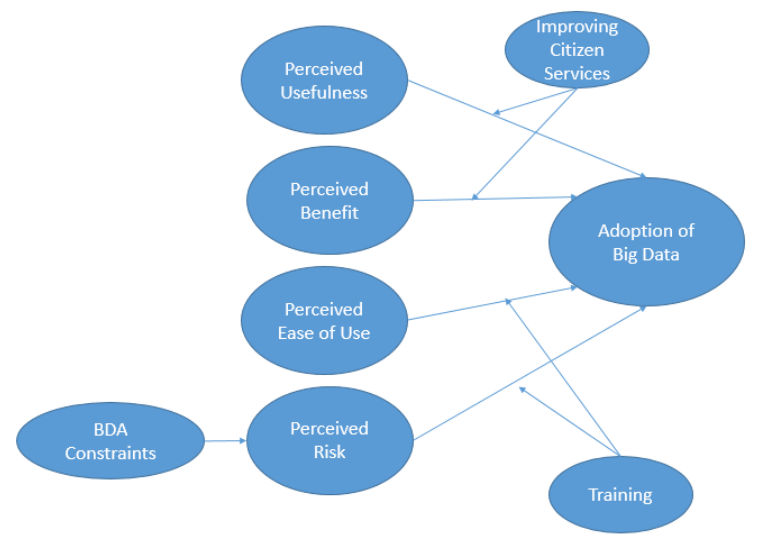

\section{References}

1. F. X. Diebold, « On the Origin(s) of the Term "Big Data" », arXiv:2008.05835 [cs, econ], août 2020, Consulté le: août 31, 2020.

2. S. Lohr, «The Origins of "Big Data": An Etymological Detective Story », Bits Blog, févr. 01, 2013.

3. D. Laney, «3D Data Management: Controlling Data Volume, Velocity, and Variety », 2001

4. OECD Observer, « Big data, satellites and climate change », 2016.

5. A. MOUMEN, « Contribution d'une approche participative et des infrastructures de données spatiales pour la conception d'un système régional d'information sur l'eau, étude de cas au bassin Guir-Ziz-Rheris et Maider », Université Ibn Tofail, 2016

6. J. Elhassan, M. Aniss, et C. Jamal, « Big Data Analytic Architecture for Water Resources Management: A Systematic Review "), in Proceedings of the 4th Edition of International Conference on Geo-IT and Water Resources 2020, Geo-IT and Water Resources 2020, New York, NY, USA, mars 2020, doi: 10.1145/3399205.3399225.

7. Davis FD. A technology acceptance model for empirically testing new end-user information systems: theory and results. Cambridge: Massachusetts Institute of Technology; 1985.

8. Khan HU, Awan MA. Possible factors affecting internet addiction: a case study of higher education students of Qatar. Int J Bus Inf Syst (IJBIS), Forthcom. 2017.

9. Fishbein M. A theory of reasoned action: some applications and implications; 1979.

10. Ajzen I. From intentions to actions: a theory of planned behavior. Berlin: Springer; 1985.

11. Davis FD. Perceived usefulness, perceived ease of use, and user acceptance of information technology. MIS Q. 1989;13(3):319-40.

12. K. W. K. Soon, C. A. Lee, and P. Boursier, 'A study of the determinants affecting adoption of big data using integrated Technology Acceptance Model (TAM) and diffusion of innovation (DOI) in Malaysia', Int. J. Appl. Bus. Econ. Res., vol. 14, no. 1, pp. 17-47, 2016.

13. V. Brock and H. U. Khan, 'Big data analytics: does organizational factor matters impact technology acceptance?', J. Big Data, vol. 4, no. 1, pp. 1-28, 2017

14. S. Verma, S. S. Bhattacharyya, and S. Kumar, 'An extension of the technology acceptance model in the big data analytics system implementation environment', Inf. Process. Manag., vol. 54, no. 5, pp. 791-806, 2018.

Fig. 6. The research model 
15. S. Okcu, G. H. Koksalmis, E. Basak, and F. Calisir, 'Factors affecting intention to use big data tools: an extended technology acceptance model', in Industrial Engineering in the Big Data Era, Springer, 2019, pp. 401-416.

16. J. Hicham, M. Aniss, et M. Bouabid, « Moroccan Water Information System: Exploratory study System Literature Review », in Proceedings of the 4th Edition of International Conference on Geo-IT and Water Resources 2020, Geo-IT and Water Resources 2020, New York, NY, USA, mars 2020, doi: $10.1145 / 3399205.3399226$.

17. MDE, 'Royal Decree No 1-95-154 Law on Water'. 1995. Accessed: Oct. 15, 2021. [Online]. Available: http://gis.nacse.org/rewab/docs/Royal_Decree_No _1-95-154_Promulgating_Law_on_Water_EN.pdf

18. F. Belamari, 'Gestion de l'Eau au Maroc dans un système complexe et incertain', 2008.

19. A. Moumen, 2020, "Adoption of Big data, Cloud Computing \& IoT in Morocco perception of public administrations collaborators", in Proceedings of the 4th Edition of International Conference on Geo-IT and Water Resources 2020, Geo-IT and Water Resources 2020, New York, NY, USA, mars 2020,

https://doi.org/10.1145/3399205.3399228 